\title{
A method to improve the selection of nursing students
}

\author{
Karen LaMartina, David Zamierowski, Mantosh Dewan \\ Johnson County Community College, Overland Park, Kansas City, United States
}

Received: April 10, 2018

DOI: $10.5430 /$ jnep.v8n12p66

\author{
Accepted: July 18, 2018 \\ Online Published: August 8, 2018 \\ URL: https://doi.org/10.5430/jnep.v8n12p66
}

\begin{abstract}
Background: Current baseline measures-primarily cognitive-do not select the best nurses. We hypothesized that a validated test of thinking skills, Strategic Management Simulations (SMS), will predict the nurses the faculty deemed the best at graduation. Methods: A total of 37 RNs in the last semester of an Associate Degree program voluntarily took the SMS. At graduation, faculty ranked them on "who would best take care of your loved one?" Faculty rank was correlated with SMS scores, admission rank and graduation end points.

Results: Faculty rank did not correlate with admission rank or cumulative grade but did with the final nursing module rank and with three SMS measures: crisis response, breadth of approach, and focused activity.

Conclusions: Traditional selection methods, e.g., admission rank, do not predict outcomes of nursing graduates, e.g., final nursing module rank. Measures of thinking, e.g., SMS crisis response, correlate with desired outcomes and could be used during the selection process to improve outcomes.
\end{abstract}

Key Words: Student nurse recruitment, Student nurse selection, Emotional intelligence, Critical thinking, Strategic management simulation

\section{BACKGROUND}

The universal goal of nursing programs is to recruit, train, and graduate the best nurses. The first important step is to attract the best students who are most likely to become good nurses ${ }^{[1]}$ and a great deal of faculty time and the program's resources are committed to this enterprise. ${ }^{[2]}$ To varying degrees, each program must invest in advertising, screening applications, selecting some for interview, and finally rank ordering them based on some combination of the applicant's academic record, scales and interview score. While there is a certain logic to this traditional and widely-employed method for selecting the "best" candidates, there is a paucity of data about its effectiveness and no agreed-upon 'best practice'. However, some available data suggests traditional methods of student selection are ineffective. ${ }^{[3,4]}$
There have been numerous attempts to define the desired outcome-a good nurse. This is difficult and different authors have attempted to define this outcome using terms such as good, best, and talented-we use these multiple terms to remain faithful to the literature and use it interchangeably to denote the highest quality. Qualitative research has attempted to discover, from a nurse's perspective, those qualities or attributes considered desirable in a nurse. One study revealed categories or themes that emerged when nurses were asked the questions, "a good nurse is one who...", and "how does a nurse go about doing the right thing?". ${ }^{[5]}$ Those themes included being professional, having a solid knowledge base, being patient-centered, and being a good critical thinker. Others have suggested that "talented nurses" provide safe, high quality care and possess attributes including intelligence and

\footnotetext{
* Correspondence: Karen LaMartina; Email: lamartin@jccc.edu; Address: Johnson County Community College, Overland Park, Kansas City, United
} States. 
competency at the bedside, both in the technical arena as well as the emotional one. ${ }^{[6]}$

For decades, numerous attempts have been made to tease out specific factors that would identify the 'right' ${ }^{[1]}$ candidate and lead to training a talented ${ }^{[6]}$ nurse from the many persons who apply to nursing school. In general, success on exams such as the National Licensure Examination-RN (NCLEX$\mathrm{RN})^{[7]}$ or rate of attrition ${ }^{[8]}$ are used as endpoints. Cognitive measures such as grade point average (GPA), ${ }^{[9,10]}$ high school class rank ${ }^{[10]}$ or American College Test (ACT) scores are routinely used to evaluate applicants. Since these are not consistently predictive, a host of non-cognitive measures have been added to the mix. These include emotional intelligence, ${ }^{[11,12]}$ a history of caring for others, ${ }^{[11]}$ personal essays, ${ }^{[8]}$ personality tests, ${ }^{[2]}$ and situational judgment tests. ${ }^{[13]}$ Methods to assess these traits include the long interview, multiple mini interviews, and letters of reference ${ }^{[13-16]}$ and again, these are not consistently helpful. This parallels the findings from other health fields that there is poor correlation between initial assessment methods and the ability to predict success. For instance, undergraduate GPA and ACT or Medical College Admissions Test (MCAT) scores may predict the likelihood of graduating from school but not how good the nurse or doctor is.

This has led education research to raise two additional questions that are important to this paper. First, are we missing other factors that predict success? Some have pointed to another important attribute, thinking skills, as the critical component. ${ }^{[17]}$ There are many models for assessment and training of thinking skills but, as with the admission process, there is a paucity of data showing which ones are most effective. LaMartina and Ward-Smith's review (2014) suggests that Strategic Management Simulation (SMS) may be a particularly good, well validated method to assess thinking skills. ${ }^{[18-20]}$ Second, how can we meaningfully identify a good nurse? Given the complexity of the team environment in which the nurse functions, it is difficult to tease out the clinical impact that a particular nurse has on patient outcome, which is considered the highest order outcome. ${ }^{[21]}$ There is no currently available objective method to affirm a 'good nurse'. An alternate, commonly used 'gold standard' (e.g., to identify 'Best Doctors') is: "who would you like to take care of your loved one?" In fact, since objective criteria are rarely available, this subjective but informed choice (with all its failings, primarily a lack of external validation) is still the best available method. It is used every day in getting a clinical referral and was the standard used in a previous study of residents in Psychiatry. ${ }^{[22]}$ Being able to identify the best nurses using this method would allow further study of the relevant factors that go into making them.

\section{METHOD}

Thirty seven out of a class of $68 \mathrm{RN}$ students in their last semester of an Associate Degree program volunteered for this project. This was not a regular course, did not acquire a grade, and neither the test or feedback involved any faculty. This project was IRB exempt because it is purely for educational purposes (a federally exempt category) and all data are de-identified. The standard numeric data was available for each of them: admission rank (which is based on GPA [40\%], ACT score [20\%], and interview score [40\%]) from their application to nursing school), and two of the most important endpoints that are available on graduation- program cumulative grade and class rank, which is based on the score on a single final nursing module. Two additional ratings were generated. First, at graduation, each nurse was rank ordered by clinical faculty based on whom they "would like to see treat their loved one." This was based on observed clinical performance throughout the program in acute care settings. This was considered the "gold standard".

Second, each student took the 80-minute, computerized Strategic Management Simulation (SMS). SMS is grounded in complexity theory and has been used since the 1960s to measure performance in complex situations. ${ }^{[18]}$ This instrument has been used in industries such as corporate America, the military, and-more recently-medicine, and has achieved high levels of predictive validity, reliability and applicability to real world settings. ${ }^{[20]}$ Health care personnel are often challenged by situations which are characterized by VUCAD, which is an acronym for volatility, uncertainty, complexity, ambiguity, and delayed feedback. This instrument is designed to determine how the participant thinks and makes decisions in these stressful or challenging situations. ${ }^{[23]}$

The computerized simulation takes participants through a simulated scenario that includes a period of crisis. Participants can collect information, strategize and plan, and must make decisions based upon the resources available. Each decision takes the participant down a path of future decision opportunities. A unique feature of SMS is that it is knowledge agnostic and the same simulation is used for corporate managers, engineers or health care professionals. This allows complexity theory-based SMS to focus purely on the "how" of decision-making i.e. that process that requires critical thinking that will ultimately lead to effective problem solving. ${ }^{[19]}$ SMS identifies decision-making ability on 25 different parameters of cognitive behavior. The most relevant for health care participants include activity level, task orientation, initiative, information management, breadth of approach, strategy, and crisis response. ${ }^{[24,25]}$ Participants receive a score for each parameter. Another unique feature of SMS is the availability of feedback and specific training 
to help improve each parameter.

SMS has been studied in resident physicians in several specialties, with evidence that surgery residents increased their competence in clinical decision making. ${ }^{[20]}$ This is the first application to nursing students.

\section{Results}

Table 1. Comparison of rankings of students using program admission rank, class rank at end of program, and faculty rank at end of program

\begin{tabular}{|c|c|c|}
\hline Faculty ranking & Class ranking & Admission ranking \\
\hline 1 & 23 & 51 \\
\hline 2 & 7 & 21 \\
\hline 3 & 26 & 10 \\
\hline 4 & 40 & 24 \\
\hline 5 & 16 & 4 \\
\hline 6 & 56 & 42 \\
\hline 7 & 10 & 62 \\
\hline 8 & 4 & 53 \\
\hline 9 & 15 & 26 \\
\hline 10 & 6 & 15 \\
\hline 11 & 11 & 69 \\
\hline 12 & 25 & 19 \\
\hline 13 & 36 & 5 \\
\hline 14 & 59 & 57 \\
\hline 15 & 13 & 5 \\
\hline 16 & 18 & 66 \\
\hline 17 & 61 & 16 \\
\hline 18 & 45 & 37 \\
\hline 19 & 44 & 43 \\
\hline 20 & 27 & 3 \\
\hline 21 & 3 & 6 \\
\hline 22 & 65 & 63 \\
\hline 23 & 12 & 4 \\
\hline 24 & 58 & 29 \\
\hline 25 & 5 & 41 \\
\hline 26 & 50 & 32 \\
\hline 27 & 14 & 13 \\
\hline 28 & 47 & 8 \\
\hline 29 & 33 & 47 \\
\hline 30 & 21 & 56 \\
\hline 31 & 64 & 20 \\
\hline 32 & 53 & 46 \\
\hline 33 & 63 & 3 \\
\hline 34 & 34 & 48 \\
\hline 35 & 54 & 12 \\
\hline 36 & 20 & 30 \\
\hline 37 & 38 & 7 \\
\hline
\end{tabular}

Faculty rank at graduation did correlate with class rank, which is the grade on the final nursing module (Pearson's $r$ $=.351, p=.039)$. It did not correlate with Admission Rank
( $r=.089, p=.610)$ or Cumulative grade $(r=.199, p=.253)$. Faculty rank also was correlated with three SMS measures of thinking: crisis response $(r=-.810, p=.000)$, breadth of approach $(r=-.526, p=.001)$, and focused activity $(r=$ $-.372, p=.028)($ see Table 1$)$.

Crisis response was the most useful measure. Not only did crisis response have the highest degree of correlation with faculty rank, it was also highly correlated with class rank $(r$ $=-.519, p=.001)$ and cumulative grade $(r=.496, p=.002)$. Demographic information, such as gender, or working status while in the nursing program, was not considered in this ranking. Faculty were simply asked to rank the students based on who they felt would be the best bedside clinicians determined by faculty observations in the clinical settings. While those variables could have a bearing on student success, they were not considered in this pilot exercise.

\section{Discussion}

There is a compelling need to profile the best nurses using objective measures. Once we profile them and establish the important elements, we can work on creating and enhancing this constellation of attributes. Our preliminary study asked faculty to rank the best nurses; we know them when we see them but it is not customary to rank the best and the worst (even though all meet minimum criteria and will graduate). We then sought to profile the best nurses using standard measures of academic achievement eg undergraduate GPA, faculty evaluation of their clinical skills eg., grade on final module, as well as a validated instrument of "how" we think which is novel to nursing education, SMS. Admission criteria in this study do not predict any of our desired or valued outcomes at graduation such as the gold standard faculty ranking of students, cumulative grade, nor class rank i.e. faculty rank did not correlate with Admission rank $(r$ $=.089, p=.610)$. This is consistent with the nursing and medicine literature and significant because Admission Rank is based on the current method, i.e., the traditional, broad based, time-intensive, strenuous attempt made to balance objective and subjective input, does not predict any of the desired outcomes. For example the study school site carries a $60 \% / 40 \%$ split of objective to subjective weight respectively in ranking potential students. Nevertheless, we persist in an expensive method for choosing nursing students, take seriously the rank order we come up with, and are disappointed enough to set up committees to study why our top-rated applicants don't accept our admission invitation. We did not get our top candidates; we just may have gotten the best ones. We do not know.

If all our admission criteria fail to predict desired outcome, what might do so? It is striking that one easily obtained, 
objective SMS measure- crisis response- was strongly predictive of faculty rank at graduation (the gold standard), class rank, and cumulative grade. All three of these desired outcome ratings can be calculated only at graduation. In contrast, a measurement of the cognitive parameter of crisis response can be obtained at any stage, including during the application process where it would be particularly useful. The SMS is not being used for this purpose in nursing but has been used as part of the admission process in a Plastic Surgery program. ${ }^{[24]}$

The three significant SMS measures model the thinking of a highly competent nurse with which we can intuitively identify. It is a person who can grasp the big picture and its multiple opportunities (breadth of approach), actively stay on task and get it done (focused activity), and step up in a crisis situation (crisis response). There are several limitations of this pilot study. The subjects are a small $(n=37)$ crosssectional, convenience sample of Associate Degree students in their last semester. To show that these SMS measures actually improve selection, this study needs to be replicated with the SMS assessment being done (but not used to influence decisions) as part of the admission process, preferably for all applicants. Then it must be shown that these three measures predicted outcome.

\section{Conclusion}

This pilot study found that three parameters of thinking on the SMS- breadth of approach, focused activity, and crisis response- define nurses that faculty rated as the best. If a larger, more rigorous study confirm these preliminary results it would suggest two steps that may produce better nurses. First, we need to recruit students who have the characteristics of the nurse graduates rated highest by faculty. The admission process would admit students with the highest scores on an evaluation of the cognitive parameters of crisis response, breadth of approach, and focused activity. GPA, ACT, and interview scores remain important and would have a minimum cutoff but would not be given further weight or consideration.

Second, nurses can continue to focus on mastering knowledge and skills while being immersed in traditional settings e.g., clinical rotations, and also train with innovative technologies e.g., high fidelity simulators. To knowledge and skills, we recommend adding what faculty valued the most: thinking skills, with particular attention to crisis response, breadth of approach, and focused activity measures. Thinking skills, especially crisis response, differentiates the good from the average nurse whereas their GPA, ACT score, and cumulative grade do not. We can recruit student nurses already gifted in these thinking parameters and, more importantly, training can also be used to improve them. ${ }^{[25]}$

SMS evaluates many parameters of thinking that are critical and predictive of success in the real world, including in the corporate and medical settings. ${ }^{[24]}$ More impressively, it goes beyond evaluation and also allows training (either remediation or enhancement) in any specific parameter. Therefore, a brief curriculum to enhance crisis response, breadth of approach and focused activity could be used to produce better nurses, nurses who are knowledgeable, skillful and good thinkers. This brief curriculum could be beneficial even toand maybe particularly for-students who were not selected based on SMS parameters. Using SMS for guiding admission decisions and for targeted training are two logical and promising next steps that need to be empirically tested with the aim of improving selection and training to consistently produce good nurses.

\section{CONFLicts OF INTEREST Disclosure}

The authors declare that there is no conflict of interest.

\section{REFERENCES}

[1] Wood C. Choosing the 'right' people for nursing: Can we recruit to care? British Journal of Nursing. 2014; 23(10): 528530. PMid:24851917 https://doi.org/10.12968/bjon. 2014 .23 .10 .528

[2] Talman K, Huli M, Puukka P, et al. The predictive value of two onsite selection methods of undergraduate nursing students: A cohort study. J Nurs Ed Pract. 2018; 8: 12-21. https://doi.org/10.5 430/jnep.v8n7p12

[3] Dawes RM. House of cards: Psychology and psychotherapy built on myth. The Free Press: New York; 1994.

[4] Timer JE, Clauson MI. The use of selective admissions tools to predict students' success in an advanced standing baccalaureate nursing program. Nurse Education Today. 2011; 31(6): 601-606.
PMid:21056921 https://doi.org/10.1016/j.nedt.2010.10 .015

[5] Smith KV, Godfrey S. Being a good nurse and doing the right thing: A qualitative study. Nursing Ethics. 2002; 9(3): 301-312. PMid:12035435 https://doi.org/10.1191/0969733002ne51 2oa

[6] Lang GM, Beach NL, Patrician PA, et al. Cross-sectional study examining factors related to critical thinking in nursing. Journal for Nurses in Professional Development. 2013; 29(1): 8-15. PMid:23486150 https://doi.org/10.1097/NND.0b013e31827d08c8

[7] McCarthy MA, Harris D, Tracz SM. Academic and nursing aptitude and the NCLEX-RN in baccalaureate programs. Journal of Nursing Education. 2014; 53(3): 151-159. https://doi.org/10.3928/ 01484834-20140220-01 
[8] Sadler J. Effectiveness of student admission essays in identifying attrition. Nursing Education Today. 2003; 23(8): 620-627. https: //doi.org/10.1016/S0260-6917(03)00112-6

[9] Cunningham C, Manier A, Anderson A, et al. Rational versus empirical prediction of nursing student success. Journal of Professional Nursing. 2014; 30(6): 486-492. PMid:25455330 https: //doi.org/10.1016/j.profnurs.2014.03.006

[10] Alichnie M. Prediction of freshman students' success in a baccalaureate nursing program. Nursing Research. 1981; 30(1): 49. https ://doi.org/10.1097/00006199-198101000-00017

[11] Snowden A, Stenhouse R, Young J, et al. The relationship between emotional intelligence, previous caring experience and mindfulness in student nurses and midwives: A cross-sectional analysis. Nursing Education Today. 2015; 35(1): 152-158. PMid:25282342 https ://doi.org/10.1016/j.nedt.2014.09.004

[12] Codier E, Odell E. Measured emotional intelligence ability and grade point average in nursing students. Nurse Education Today. 2014; 34(4): 608-612. PMid:23835081 https://doi.org/10.1016/j . nedt. 2013.06.007

[13] Sui E, Reiter H. Overview: What's worked and what hasn't as a guide towards predictive admissions tool development. Advances in Health Sciences Education. 2009; 14: 759-775. PMid:19340597 https://doi.org/10.1007/s10459-009-9160-8

[14] Ehrenfield M, Tabak N. Value of admission interviews in selecting of undergraduate nursing students. Journal of Nursing Management. 2000; 8(2): 101-106. https://doi.org/10.1046/j.1365-283 4.2000.00155.x

[15] Rees EL, Hawarden AW, Dent G, et al. Evidence regarding the utility of multiple mini-interview (MMI) for selection to undergraduate health programs: A BEME systematic review. Medical Teacher. 2016; 38(5): 443-455. PMid:27050026 https : //doi .org/10.3109/01 42159X. 2016.1158799
[16] Gale J. Selection and MMI. Nursing Education Today. 2016; 40: 123-127. PMid:27125161

[17] LaMartina K, Ward-Smith P. Developing critical thinking skills in undergraduate nursing students: The potential for strategic management simulations. Journal of Nursing Education and Practice. 2014; 4(9): 155-162. https://doi.org/10.5430/jnep.v4n9p155

[18] Streufert S, Pogash R, Piasecki M. Simulation-based assessment and managerial competence: Reliability and validity. Personnel Psychology. 1988; 41: 537-557. https://doi.org/10.1111/j.1744-6 570.1988. tb00643.x

[19] Satish U, Streufert S, Marshall R, et al. Strategic management simulations is a novel way to measure resident competencies. The American Journal of Surgery. 2001; 181: 557-561. https ://doi .org/10.1 016/S0002-9610(01) 00630-4

[20] Satish U, Krummel T, Foster T, et al. Using strategic management simulation to evaluate physician competence: A challenge and a vision. ACGME Bulletin. 2005; 19-21.

[21] Kirkpatrick D, Kirkpatrick J. Evaluating Training Programs. BerrettKoehler Publishers; 1994.

[22] Satish U, Manring J, Gregory R, et al. Novel assessment of Psychiatric residents: SMS simulations. ACGME Bulletin. 2009; 1: 18-23.

[23] Satish U, Streufert S. Value of cognitive simulation in medicine: Towards optimizing decision-making performance of healthcare personnel. Quality and Safety in Health Care. 2002; 11(2): 163-167. https://doi.org/10.1136/qhc.11.2.163

[24] Krishnamurthy S, Satish U, Dewan M. Role of cognitive simulation in healthcare. In Riley R (Ed): Manual of simulation in healthcare. Oxford U Press; London: 2015.

[25] Satish U, Streufert S, Eslinger PJ. Simulation-based executive cognitive assessment and rehabilitation after traumatic frontal lobe injury: A case report. Disability and Rehabilitation. 2008; 30(6): 468-478. PMid:18297501 https://doi.org/10.1080/09638280701625 401 